\title{
Chronic digitalis therapy in patients before heart transplantation is an independent risk factor for increased posttransplant mortality
}

This article was published in the following Dove Press journal:

Therapeutics and Clinical Risk Management

13 October 2017

Number of times this article has been viewed

\author{
Rasmus Rivinius' \\ Matthias Helmschrott ${ }^{\prime}$ \\ Arjang Ruhparwar ${ }^{2}$ \\ Ann-Kathrin Rahm ${ }^{1,3}$ \\ Fabrice F Darche \\ Dierk Thomas' \\ Tom Bruckner ${ }^{4}$ \\ Philipp Ehlermann' \\ Hugo A Katus' \\ Andreas O Doesch ${ }^{1,5}$ \\ 'Department of Cardiology, Angiology \\ and Pneumology, Heidelberg \\ University Hospital, Heidelberg, \\ ${ }^{2}$ Department of Cardiac Surgery, \\ Heidelberg University Hospital, \\ Heidelberg, ${ }^{3}$ Faculty of Medicine, \\ University of Heidelberg, Heidelberg, \\ ${ }^{4}$ Institute for Medical Biometry and \\ Informatics, University of Heidelberg, \\ Heidelberg, ${ }^{5}$ Asklepios Klinik Bad \\ Salzungen $\mathrm{GmbH}$, Department of \\ Pneumology and Oncology, Bad \\ Salzungen, Germany
}

Objectives: Digitalis therapy (digoxin or digitoxin) in patients with heart failure is subject to an ongoing debate. Recent data suggest an increased mortality in patients receiving digitalis. This study investigated the effects of chronic digitalis therapy prior to heart transplantation (HTX) on posttransplant outcomes.

Patients and methods: This was a retrospective, observational, single-center study. It comprised 530 adult patients who were heart-transplanted at Heidelberg University Hospital between 1989 and 2012. Patients with digitalis prior to HTX ( $\geq 3$ months) were compared to those without (no or $<3$ months of digitalis). Patients with digitalis were further subdivided into patients receiving digoxin or digitoxin. Primary outcomes were early posttransplant atrial fibrillation and mortality.

Results: A total of 347 patients $(65.5 \%)$ had digitalis before HTX. Of these, 180 received digoxin (51.9\%) and 167 received digitoxin (48.1\%). Patients with digitalis before HTX had a significantly lower 30-day ( $P=0.0148)$ and 2-year $(P=0.0473)$ survival. There was no significant difference between digoxin and digitoxin in 30-day $(P=0.9466)$ or 2 -year $(P=0.0723)$ survival. Multivariate analysis for posttransplant 30-day mortality showed pretransplant digitalis therapy as an independent risk factor (hazard ratio $=2.097$, CI: $1.036-4.248, P=0.0397$ ). Regarding atrial fibrillation in the early posttransplant period, there was neither a statistically significant difference between patients with and without digitalis $(P=0.1327)$ nor between patients with digoxin or digitoxin $(P=0.5867)$.

Conclusion: Digitalis in patients before HTX is an independent risk factor for increased posttransplant mortality.

Keywords: atrial fibrillation, digitalis, heart transplantation, mortality

\section{Introduction}

Digitalis (digoxin or digitoxin) has been used in the treatment of congestive heart failure and/or atrial fibrillation (AF) for several decades. ${ }^{1,2}$ As a result, there is an ongoing debate about the use of digitalis as concerns have been raised about its efficacy and safety. There are several reports about a higher mortality in patients receiving digitalis, ${ }^{2-10}$ while others could not detect a statistically significant difference and suggested that an association between digitalis and adverse outcomes could be due to confounding and selection bias. ${ }^{11-13}$ Moreover, independently performed post hoc analyses of the AFFIRM study ${ }^{14}$ yielded diverging results as a consequence of different statistical tools. ${ }^{15-18}$

In the light of the narrow therapeutic window of digitalis, a possible reason for the conflicting data could be the applied daily dose of digitalis, as elevated serum levels
Correspondence: Andreas O Doesch Department of Cardiology, Angiology and Pneumology, Heidelberg University Hospital, Im Neuenheimer Feld 4I0, 69120 Heidelberg, Germany

Tel +496221568676

$\mathrm{Fax}+496221565515$

Email klinische.herztransplantation@ med.uni-heidelberg.de 
of digitalis have been linked to an increased mortality due to drug interactions and arrhythmic disorders. ${ }^{2,15}$ Furthermore, dosing strategies and serum level monitoring of digitalis can vary immensely, potentially affecting the outcomes. ${ }^{19,20}$

The primary mechanism of action of digitalis is inhibition of sodium/potassium adenosine triphosphatase, leading to an elevated intracellular sodium concentration. As a consequence, there is a reduced sodium/calcium exchanger activity, leading to an increase in intracellular calcium concentration. This elevated calcium level is assumed to stimulate myocardial contraction (positive inotropic effect). ${ }^{21,22}$ Moreover, digitalis also shows effects on the cardiac conduction system by decreasing the heart rate (negative chronotropic effect), reducing the conduction velocity (negative dromotropic effect), and increasing cellular excitability (positive bathmotropic effect), resulting in bradycardia, atrioventricular block, and cardiac arrhythmias. ${ }^{21,22}$

Furthermore, extracardiac effects of digitalis include sensitization of baroreceptors located in the carotid sinus region, modulation of smooth muscle tone, and stimulation of the central vagal nucleus. ${ }^{22-24}$

As part of heart failure (HF) medication, many patients receive digitalis before heart transplantation (HTX). ${ }^{1,2}$ However, little is known about the transient effects of prior digitalis therapy on posttransplant outcomes. Hence, this study investigated the effects of chronic digitalis therapy prior to HTX on AF in the early posttransplant period, as well as mortality after HTX.

\section{Patients and methods}

\section{Patients}

The performance of this study was approved by the ethical review board of the University of Heidelberg and was in accordance with the Declaration of Helsinki. It comprised all patients ( $\geq 18$ years) who were heart-transplanted at Heidelberg University Hospital between June 1989 and December 2012. Cardiac re-transplantations were excluded. Data were retrieved from the clinical routine and analyzed in pseudonymized form. No additional written informed consent was required for this retrospective observational single-center study, as only clinical routine data were used..$^{25-28}$

Patients were stratified by digitalis treatment prior to HTX: patients with $\geq 3$ months of digitalis therapy directly before HTX were included in the "chronic digitalis" group, while patients with no or $<3$ months of digitalis use prior to HTX were included in the "no chronic digitalis" group. Patients with intermittent or former (determined $>90$ days before HTX) digitalis therapy were put in the "no chronic digitalis" group.
Patients with chronic digitalis were further subdivided into patients receiving digoxin or digitoxin. Additionally, daily dosage (milligrams) and duration (days) of pretransplant digoxin and digitoxin treatment were assessed. Indication for digitalis therapy before HTX was HF with or without AF.

\section{Follow-up}

Posttransplant follow-up of patients was performed in line with the center standard. Patients were routinely supervised by ongoing heart rhythm monitoring while in hospital. Moreover, 12-lead electrocardiography was regularly carried out and in the event of arrhythmias on monitoring. Additionally, Holter monitoring for 24 hours was routinely conducted. Assessment of heart rhythm in the early posttransplant period ( $\leq 30$ days following HTX) was based upon all available source files. The definition of early posttransplant AF was that AF was documented for a minimum period of 30 seconds within 30 days following HTX. Other atrial arrhythmias were excluded. ${ }^{25-27}$

After discharge, patients were followed up monthly within 6 months following HTX, then every 2 months until 12 months after HTX, and thereafter three to four times annually. Routine follow-up appointments comprised anamnesis, physical examination, electrocardiography, blood tests, dose adjustment of immunosuppressive drug therapy, and performance of echocardiography. ${ }^{25-30}$

\section{Medication following HTX}

Patients received immunosuppressive drug therapy and posttransplant medication conforming to the center standard. Since 1994, an immunosuppressive induction treatment with anti-thymocyte globulin has been applied to patients after HTX. Cyclosporine A (CsA) and azathioprine (AZA) were used as initial immunosuppressive drug therapy. AZA was subsequently substituted by mycophenolate mofetil from 2001 onward, and CsA was consecutively replaced by tacrolimus from 2006 onward. Steroids were additionally administered in the initial period after HTX. ${ }^{25-28}$

\section{Statistical analysis}

Data analysis was carried out with SAS software (Version 9.3; SAS Institute, Cary, NC, USA). Results were presented as count $(n)$ with percentage $(\%)$ or as mean \pm standard deviation. Categorical variables were analyzed with chi-squared test, and continuous variables with Student's $t$-test. Posttransplant survival and absence of AF in the early posttransplant period were displayed with Kaplan-Meier estimators. A $P$-value of $<0.0500$ was considered as statistically significant. ${ }^{25-28}$ 
Univariate analyses included recipient data, donor data, and perioperative data. A multivariate analysis for mortality within 30 days after HTX was conducted using Cox regression to analyze the impact of different variables that were statistically significant in the univariate analysis. It included the following six variables: chronic digitalis therapy before HTX, diabetes mellitus, nonischemic cardiomyopathy (CMP), cardiac amyloidosis, biatrial HTX, and bicaval HTX. No additional variables were selected for this multivariate analysis to provide a stable number of events (deceased patients) per analyzed variable and to avoid biased regression coefficients.

Primary outcomes of this study were mortality after HTX and AF within 30 days following HTX.

\section{Results}

\section{Demographic and clinical characteristics}

This retrospective observational single-center study comprised a total of 530 patients. Of these, 347 patients $(65.5 \%)$ received chronic digitalis therapy before HTX and 183 patients (34.5\%) had no chronic digitalis therapy prior to HTX. Patients with chronic digitalis use prior to HTX were further subdivided into 180 patients $(51.9 \%)$ with digoxin and 167 patients $(48.1 \%)$ with digitoxin.

In terms of recipient data, no significant differences were observed between the groups concerning age $(P=0.7164)$, male sex $(P=0.4745)$, body mass index $(P=0.0793)$, coronary artery disease $(P=0.5354)$, arterial hypertension $(P=0.7750)$, dyslipidemia $(P=0.5615)$, renal insufficiency $(P=0.1245)$, or glomerular filtration rate $(P=0.9753)$. Patients with chronic digitalis use before HTX showed a significantly higher percentage of diabetes mellitus (131/347 [37.8\%] vs 51/183 [27.9\%], $P=0.0227$ ).

Regarding the principal diagnoses for HTX, a significantly higher rate of patients with nonischemic CMP was found in the chronic digitalis group (204/347 [58.8\%] vs $80 / 183$ [43.7\%], $P=0.0009$ ), while a significantly higher rate of patients with cardiac amyloidosis was observed in the no chronic digitalis group (6/347 [1.7\%] vs 30/183 [16.4\%], $P<0.0001)$. No statistically significant differences were observed between groups for ischemic CMP $(P=0.3856)$ or valvular heart disease $(P=0.1069)$ as the principal diagnosis for HTX.

In terms of donor data, age $(P=0.0713)$, male sex $(P=0.1501)$, and body mass index $(P=0.1622)$ were not significantly different. Furthermore, no significant differences were observed between groups in transplant sex mismatch $(P=0.7219)$, total orthotopic HTX $(P=0.1291)$, or duration of initial hospital stay $(P=0.4396)$.
Patients in the chronic digitalis group had a higher percentage of biatrial HTX (124/347 [35.8\%] vs 37/183 [20.2\%], $P=0.0002$ ), whereas patients in the no chronic digitalis group had a higher rate of bicaval HTX (65/347 [18.7\%] vs 50/183 [27.3\%], $P=0.0225)$. Analysis of posttransplant medication indicated no significant differences between groups concerning the administration of acetylsalicylic acid ( $P=0.5285), \beta$-blocker $(P=0.1421)$, calcium channel blocker in general $(P=0.5885)$, dihydropyridine calcium channel blocker $(P=0.9037)$, non-dihydropyridine calcium channel blocker $(P=0.4496)$, or angiotensin-converting enzyme inhibitor/angiotensin II receptor blocker $(P=0.2815)$. Demographic and clinical characteristics including posttransplant medication are given in Table 1.

\section{Indications for digitalis therapy}

Indications for chronic digitalis use before HTX were $\mathrm{HF}$ in 183 patients $(52.7 \%)$ and $\mathrm{HF}$ with $\mathrm{AF}$ in 164 patients (47.3\%). Chronic digoxin use before HTX was applied in 110 patients $(61.1 \%)$ with $\mathrm{HF}$ and 70 patients $(38.9 \%)$ with HF with AF. Chronic digitoxin therapy before HTX was used in 73 patients (43.7\%) with $\mathrm{HF}$ and 94 patients $(56.3 \%)$ with HF with AF.

\section{Duration and daily doses of digitalis}

Mean duration of chronic digitalis therapy before HTX was 24.6 \pm 20.9 months, ranging from 3 to 148 months. Patients with chronic digoxin use prior to HTX had a mean daily dose of $0.19 \pm 0.05 \mathrm{mg}$ and a mean duration of intake of $24.0 \pm 20.8$ months, ranging from 3 to 148 months.

Patients with chronic digitoxin use prior to HTX had a mean daily dose of $0.08 \pm 0.02 \mathrm{mg}$ and a mean duration of intake of $25.2 \pm 21.1$ months, ranging from 3 to 121 months.

\section{Posttransplant survival}

A total of 254 patients (47.9\%) deceased during overall follow-up. Kaplan-Meier estimator showed an inferior 30-day $(P=0.0148)$ and 2-year $(P=0.0473)$ survival in patients with chronic digitalis therapy before HTX, in comparison to patients without chronic digitalis therapy before HTX. Kaplan-Meier analysis for 30-day survival posttransplant is presented in Figure 1 and for 2-year posttransplant survival is shown in Figure 2. Additionally, no significant difference was found between patients with digoxin or digitoxin before HTX in 30-day ( $P=0.9466)$ or 2-year posttransplant survival $(P=0.0723)$. Moreover, there was neither a statistically significant difference between patients with low or high doses of digoxin before HTX in 30-day $(P=0.5360)$ or 2 -year 
Table I Demographic and clinical characteristics

\begin{tabular}{|c|c|c|c|}
\hline Parameter & $\begin{array}{l}\text { Chronic digitalis } \\
\text { before HTX }(n=347)\end{array}$ & $\begin{array}{l}\text { No chronic digitalis } \\
\text { before HTX }(n=\mid 83)\end{array}$ & $P$-value \\
\hline \multicolumn{4}{|l|}{ Recipient data } \\
\hline Age in years, mean $\pm S D$ & $51.9 \pm 10.4$ & $51.5 \pm 10.5$ & 0.7164 \\
\hline Male sex, n (\%) & $273(78.7)$ & $139(76.0)$ & 0.4745 \\
\hline Body mass index $\left(\mathrm{kg} / \mathrm{m}^{2}\right)$, mean $\pm S D$ & $24.6 \pm 3.8$ & $25.2 \pm 3.9$ & 0.0793 \\
\hline Coronary artery disease, n (\%) & 142 (40.9) & $80(43.7)$ & 0.5354 \\
\hline Arterial hypertension, $\mathrm{n}(\%)$ & $187(53.9)$ & $101(55.2)$ & 0.7750 \\
\hline Dyslipidemia, n (\%) & $225(64.8)$ & $114(62.3)$ & 0.5615 \\
\hline Diabetes mellitus, $\mathrm{n}(\%)$ & $|3|(37.8)$ & $5 I(27.9)$ & $0.0227^{*}$ \\
\hline Renal insufficiency, ${ }^{\wedge}(\%)$ & $208(59.9)$ & $97(53.0)$ & 0.1245 \\
\hline Glomerular filtration rate, mean $\pm S D$ & $60.5 \pm 19.4$ & $60.4 \pm 23.4$ & 0.9753 \\
\hline \multicolumn{4}{|l|}{ Principal diagnosis for HTX } \\
\hline Nonischemic CMP, n (\%) & $204(58.8)$ & $80(43.7)$ & $0.0009 *$ \\
\hline Ischemic CMP, n (\%) & $114(32.9)$ & $67(36.6)$ & 0.3856 \\
\hline Valvular heart disease, n (\%) & $23(6.6)$ & $6(3.3)$ & 0.1069 \\
\hline Cardiac amyloidosis, n (\%) & $6(1.7)$ & $30(16.4)$ & $<0.000 I^{*}$ \\
\hline \multicolumn{4}{|l|}{ Donor data } \\
\hline Age in years, mean $\pm S D$ & $38.9 \pm 13.0$ & $4 I .1 \pm 13.6$ & $0.07 \mid 3$ \\
\hline Male sex, n (\%) & $163(47.0)$ & $74(40.4)$ & 0.1501 \\
\hline Body mass index $\left(\mathrm{kg} / \mathrm{m}^{2}\right)$, mean $\pm \mathrm{SD}$ & $24.4 \pm 3.6$ & $24.9 \pm 4.5$ & 0.1622 \\
\hline \multicolumn{4}{|l|}{ Transplant sex mismatch } \\
\hline Mismatch, n (\%) & I 48 (42.7) & $81(44.3)$ & 0.7219 \\
\hline Donor $(\mathrm{m})$ to recipient $(\mathrm{f}), \mathrm{n}(\%)$ & $19(5.5)$ & $8(4.4)$ & 0.5826 \\
\hline Donor $(\mathrm{f})$ to recipient $(\mathrm{m}), \mathrm{n}(\%)$ & $129(37.2)$ & $73(39.9)$ & 0.5406 \\
\hline \multicolumn{4}{|l|}{ Perioperative data } \\
\hline Biatrial HTX, n (\%) & $124(35.8)$ & $37(20.2)$ & $0.0002 *$ \\
\hline Bicaval HTX, n (\%) & $65(I 8.7)$ & $50(27.3)$ & $0.0225^{*}$ \\
\hline Total orthotopic HTX, n (\%) & $158(45.5)$ & $96(52.5)$ & 0.1291 \\
\hline LOS (days), mean \pm SD & $42.5 \pm 23.7$ & $44.0 \pm 20.4$ & 0.4396 \\
\hline \multicolumn{4}{|l|}{ Initial posttransplant medication } \\
\hline ASA, $n(\%)$ & $25(7.2)$ & $16(8.7)$ & 0.5285 \\
\hline$\beta$-Blocker, n (\%) & $46(13.3)$ & $33(18.0)$ & 0.1421 \\
\hline Calcium channel blocker, n (\%) & $87(25.1)$ & $42(22.9)$ & 0.5885 \\
\hline Dihydropyridine, n (\%) & $33(9.5)$ & $18(9.8)$ & 0.9037 \\
\hline Non-dihydropyridine, n (\%) & $54(15.6)$ & $24(13.1)$ & 0.4496 \\
\hline ACE inhibitor/ARB, $n(\%)$ & $163(47.0)$ & $77(42.1)$ & 0.2815 \\
\hline Diuretic, n (\%) & $347(100.0)$ & $183(100.0)$ & na \\
\hline Gastric protection (PPI/H2 blocker), n (\%) & $347(100.0)$ & $183(100.0)$ & na \\
\hline
\end{tabular}

Notes: ^Glomerular filtration rate $<60 \mathrm{~mL} / \mathrm{min} / 1.73 \mathrm{~m}^{2}$; *statistically significant $(P<0.0500)$.

Abbreviations: ASA, acetylsalicylic acid; ACE inhibitor, angiotensin-converting enzyme inhibitor; ARB, angiotensin II receptor blocker; CMP, cardiomyopathy; f, female; $\mathrm{H} 2$ blocker, histamine receptor blocker; HTX, heart transplantation; LOS, length of initial hospital stay; m, male; n, number; na, not applicable; PPI, proton pump inhibitor; $\mathrm{SD}$, standard deviation.

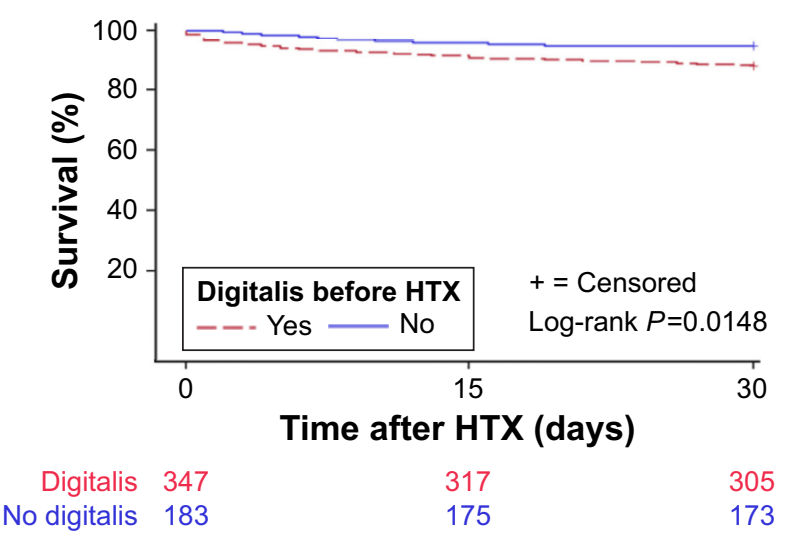

Figure I Thirty-day survival after HTX (Kaplan-Meier estimator).

Note: Patients with chronic digitalis therapy before HTX had a statistically significant inferior 30-day posttransplant survival, compared to patients without chronic digitalis therapy before HTX $(P=0.0148)$.

Abbreviation: HTX, heart transplantation.

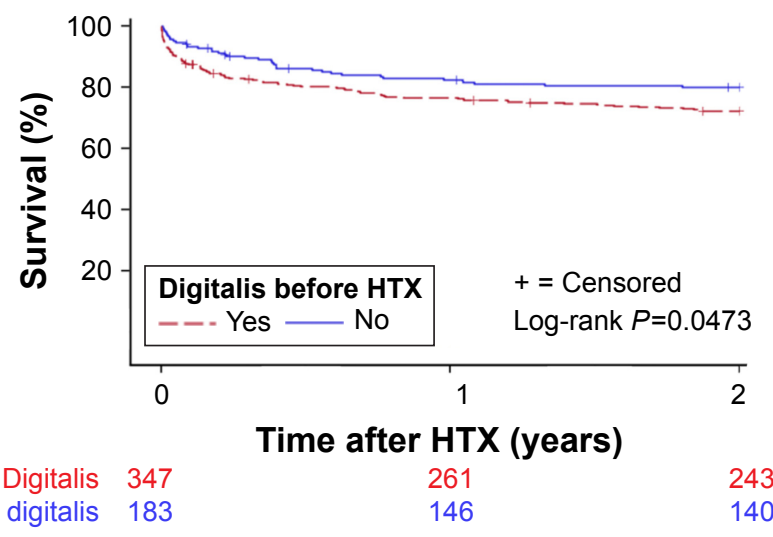

Figure 2 Two-year survival after HTX (Kaplan-Meier estimator).

Note: Patients with chronic digitalis therapy before HTX had a statistically significant inferior 2-year posttransplant survival, compared to patients without chronic digitalis therapy before $\mathrm{HTX}(P=0.0473)$.

Abbreviation: HTX, heart transplantation. 
$(P=0.1997)$ survival nor between patients with low or high doses of digitoxin before HTX in 30-day $(P=0.4199)$ or 2-year posttransplant survival $(P=0.3484)$.

\section{Multivariate analysis}

Multivariate analysis for posttransplant 30-day mortality comprised the following six variables: chronic digitalis therapy before HTX (hazard ratio $[\mathrm{HR}]=2.097$, 95\% CI: 1.036-4.248, $P=0.0397)$, diabetes mellitus (HR $=0.868$, CI: $0.488-1.542, P=0.6282)$, nonischemic CMP (HR $=0.661$, CI: $0.381-1.147, P=0.1414)$, cardiac amyloidosis (HR $=0.327$, CI: 0.042-2.510, $P=0.2821$ ), biatrial HTX (HR $=1.228$, CI: 0.675-2.234, $P=0.5004)$, and bicaval HTX (HR $=0.779$, CI: $0.350-1.736, P=0.5419)$. Multivariate analysis is displayed in Table 2 .

\section{Causes of death}

A total of 52 patients $(9.8 \%)$ deceased within 30 days following HTX. Forty-two of 347 patients (12.1\%) passed away in the chronic digitalis group, while 10 of 183 patients (5.4\%) deceased in the no chronic digitalis group $(P=0.0146)$. In terms of causes of death, significantly more patients died from transplant failure in the chronic digitalis group (31/347 [8.9\%] vs 6/183 [3.3\%], $P=0.0151)$, while there were no statistically significant differences in acute rejection $(P=0.6448)$, infection/sepsis $(P=0.4335)$, or stroke/ intracranial hemorrhage $(P=0.6874)$. Causes of death are shown in Table 3.

\section{Echocardiographic features}

Patients with chronic digitalis use before HTX showed a significantly higher rate of reduced left ventricular ejection fraction (LVEF; 39/347 [11.2\%] vs 9/183 [4.9\%], $P=0.0159$ ) and an enlarged left ventricular size (31/347 [8.9\%] vs 7/183 [3.8\%], $P=0.0302)$. Additionally, the right atrial (177/347 [51.0\%] vs $65 / 183$ [35.5\%], $P=0.0007)$ and the left atrial (200/347 [57.6\%] vs 77/183 [42.1\%], $P=0.0006)$ end-diastolic

Table 2 Multivariate analysis for mortality within 30 days after HTX

\begin{tabular}{llll}
\hline Variable & $\begin{array}{l}\text { Hazard } \\
\text { ratio }\end{array}$ & $\begin{array}{l}\text { 95\% confidence } \\
\text { interval }\end{array}$ & P-value \\
\hline $\begin{array}{l}\text { Chronic digitalis therapy } \\
\text { before HTX (in total) }\end{array}$ & 2.097 & $1.036-4.248$ & $0.0397^{*}$ \\
$\begin{array}{llll}\text { Diabetes mellitus (in total) } \\
\text { Nonischemic CMP (in total) }\end{array}$ & 0.868 & $0.488-\mathrm{I} .542$ & 0.6282 \\
Cardiac amyloidosis (in total) & 0.327 & $0.38 \mathrm{I}-\mathrm{I} . \mathrm{I} 47$ & $0.14 \mathrm{I}$ \\
Biatrial HTX (in total) & $\mathrm{I} .228$ & $0.675-2.52 .510$ & $0.282 \mathrm{I}$ \\
Bicaval HTX (in total) & 0.779 & $0.350-\mathrm{I} .736$ & 0.5004 \\
\hline
\end{tabular}

Note: *Statistically significant $(P<0.0500)$.

Abbreviations: CMP, cardiomyopathy; HTX, heart transplantation.
Table 3 Causes of death within 30 days after HTX

\begin{tabular}{llll}
\hline Parameter & $\begin{array}{l}\text { Chronic } \\
\text { digitalis before } \\
\text { HTX (n=347) }\end{array}$ & $\begin{array}{l}\text { No chronic } \\
\text { digitalis before } \\
\text { HTX (n=183) }\end{array}$ & P-value \\
\hline Transplant failure, n (\%) & $3 \mathrm{I}(8.9)$ & $6(3.3)$ & $0.015 \mathrm{I}^{*}$ \\
Acute rejection, n (\%) & $\mathrm{I}(0.3)$ & $\mathrm{I}(0.5)$ & 0.6448 \\
Infection/sepsis, n (\%) & $7(2.0)$ & $2(1 . \mathrm{I})$ & 0.4335 \\
Stroke/ICH, n (\%) & $3(0.9)$ & $\mathrm{I}(0.5)$ & 0.6874 \\
All causes, n (\%) & $42(12.1)$ & $10(5.4)$ & $0.0146^{*}$ \\
\hline
\end{tabular}

Note: *Statistically significant $(P<0.0500)$.

Abbreviations: HTX, heart transplantation; $\mathrm{ICH}$, intracranial hemorrhage; n, number.

diameters were significantly more often enlarged in patients with chronic digitalis therapy before HTX.

No significant differences were observed between groups in right ventricular size $(P=0.1140)$, mitral regurgitation ( $P=0.9155)$, or tricuspid regurgitation $(P=0.2576)$. Echocardiographic features within 30 days after HTX are shown in Table 4.

\section{Atrial fibrillation}

There was no statistically significant difference between patients with and without chronic digitalis use before HTX,

Table 4 Echocardiographic features within 30 days after HTX

\begin{tabular}{|c|c|c|c|}
\hline Parameter & $\begin{array}{l}\text { Chronic } \\
\text { digitalis } \\
\text { before HTX } \\
(n=347)\end{array}$ & $\begin{array}{l}\text { No chronic } \\
\text { digitalis } \\
\text { before HTX } \\
(n=183)\end{array}$ & $P$-value \\
\hline \multicolumn{4}{|l|}{ End-diastolic diameter } \\
\hline Normal RA (<35 mm), n (\%) & I $70(49.0)$ & II 8 (64.5) & $0.0007^{*}$ \\
\hline Normal LA $(<40 \mathrm{~mm}), \mathrm{n}(\%)$ & $147(42.4)$ & $106(57.9)$ & $0.0006^{*}$ \\
\hline Normal RV (<30 mm), n (\%) & $285(82.1)$ & $160(87.4)$ & 0.1140 \\
\hline Normal LV (<55 mm), n (\%) & $316(91.1)$ & $176(96.2)$ & $0.0302 *$ \\
\hline \multicolumn{4}{|l|}{ LVEF } \\
\hline$\geq 55 \%, \mathrm{n}(\%)$ & $308(88.8)$ & $174(95.1)$ & $0.0159 *$ \\
\hline$<55 \%, \mathrm{n}(\%)$ & $39(11.2)$ & $9(4.9)$ & \\
\hline $45 \%-54 \%, n(\%)$ & $9(2.6)$ & $3(1.6)$ & \\
\hline $30 \%-44 \%, n(\%)$ & $7(2.0)$ & $0(0.0)$ & \\
\hline$<30 \%, \mathrm{n}(\%)$ & $23(6.6)$ & $6(3.3)$ & \\
\hline \multicolumn{4}{|l|}{ Mitral regurgitation } \\
\hline No, n (\%) & $265(76.4)$ & $139(76.0)$ & 0.9155 \\
\hline Yes, n (\%) & $82(23.6)$ & $44(24.0)$ & \\
\hline Mild, n (\%) & $81(23.3)$ & $42(22.9)$ & \\
\hline Moderate, n (\%) & I $(0.3)$ & $2(I . I)$ & \\
\hline Severe, n (\%) & $0(0.0)$ & $0(0.0)$ & \\
\hline \multicolumn{4}{|l|}{ Tricuspid regurgitation } \\
\hline No, n (\%) & $216(62.2)$ & $123(67.2)$ & 0.2576 \\
\hline Yes, n (\%) & $|3|(38.8)$ & $60(32.8)$ & \\
\hline Mild, n (\%) & $76(21.9)$ & $36(19.7)$ & \\
\hline Moderate, n (\%) & $32(9.3)$ & $20(10.9)$ & \\
\hline Severe, $\mathrm{n}(\%)$ & $23(6.6)$ & $4(2.2)$ & \\
\hline
\end{tabular}

Note: *Statistically significant $(P<0.0500)$.

Abbreviations: HTX, heart transplantation; LA, left atrium; LV, left ventricle; LVEF, left ventricular ejection fraction; $\mathrm{n}$, number; $\mathrm{RA}$, right atrium; $\mathrm{RV}$, right ventricle. 


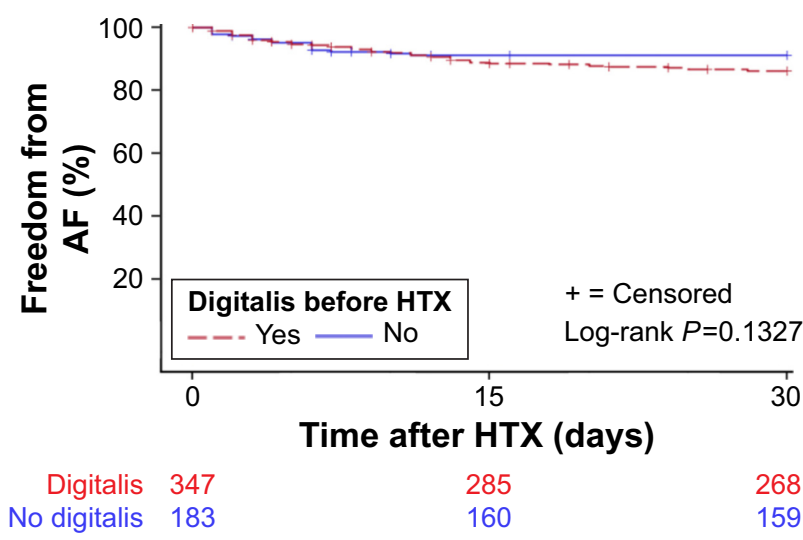

Figure 3 Freedom from early posttransplant atrial fibrillation (Kaplan-Meier estimator).

Note: There was no statistically significant difference between patients with and without chronic digitalis therapy before HTX in the occurrence of 30-day posttransplant $A F(P=0.1327)$.

Abbreviations: $A F$, atrial fibrillation; $H T X$, heart transplantation.

regarding the occurrence of AF within 30 days after HTX $(P=0.1327)$. Kaplan-Meier analysis of freedom from early posttransplant AF is given in Figure 3.

Additionally, chi-squared test showed no association between chronic pretransplant digitalis therapy and early AF after HTX $(P=0.1473)$. Moreover, there was no significant difference in terms of AF between patients with chronic use of digoxin or digitoxin before HTX $(P=0.5867)$.

\section{Discussion Digitalis therapy}

As digitalis-associated mortality is subject to an ongoing debate, this retrospective observational single-center study with 530 patients investigated the effects of chronic digitalis therapy before HTX on posttransplant mortality and AF in the early posttransplant period. Chronic digitalis therapy before HTX was associated with a significantly lower 30-day ( $P=0.0148)$ and 2-year $(P=0.0473)$ survival. Patients with chronic digitalis use prior to HTX had a significantly higher rate of reduced LVEF $(P=0.0159)$ and transplant failure ( $P=0.0151$ ). Regarding the occurrence of early posttransplant $\mathrm{AF}$, there was no significant difference between patients with and without digitalis $(P=0.1327)$.

Two modes of action should be considered when looking at the effects of pretransplant digitalis therapy in patients after HTX: 1) the influence of the remaining serum level of digitalis on the cardiac allograft which has not been exposed to digitalis before (direct cardiac effects) and 2) the repercussions of digitalis-induced extracardiac changes (sensitization of baroreceptors, modulation of smooth muscle tone, and stimulation of the central vagal nucleus) on the cardiac allograft which was adapted to "normal" physiologic properties (indirect cardiac effects).

Moreover, a third mode of action has to be taken into consideration, which is closely connected with the indirect cardiac effects. Due to differences between digoxin and digitoxin in half-life and mechanism of elimination, ${ }^{31}$ residuals of digitalis-induced extracardiac effects may vary in duration and intensity. Once the effects of digitalis fade away, a counterreaction or rebound effect may occur, including tachycardia, arrhythmias, or fluctuation of blood pressure.

Hence, all the abovementioned characteristics should be carefully considered to understand the complex consequences of pretransplant digitalis use on outcomes after HTX.

\section{Mortality after heart transplantation}

Various studies have analyzed the effects of digitalis on survival in patients with congestive heart failure and/or AF. ${ }^{1-18}$ This study is the first to investigate the effects of digitalis therapy before HTX on posttransplant survival. We observed a statistically significant impaired 30-day and 2-year survival after HTX in patients with pretransplant chronic digitalis therapy, in comparison to patients without chronic digitalis use before HTX.

Since patient selection and confounding may influence survival, demographic and clinical characteristics of patients with and without digitalis before HTX were compared. Patients in the digitalis group had a higher percentage of diabetes mellitus, nonischemic CMP as the principal diagnosis for HTX, and biatrial HTX technique, whereas patients in the no digitalis group showed a higher percentage of cardiac amyloidosis as the principal diagnosis for HTX and bicaval HTX technique. For further analysis, a multivariate analysis for posttransplant 30-day mortality was performed including the abovementioned five variables and pretransplant chronic digitalis use.

Here, only chronic digitalis therapy before HTX could be identified as a statistically significant risk factor for mortality with an HR of 2.1, indicating that patients with former digitalis use have a more than two-fold increased risk of death within 30 days after HTX.

Regarding the causes of death, significantly more patients deceased from transplant failure in the digitalis group (8.9\%) compared to the no digitalis group $(3.3 \%)$. This is in line with the observed findings of a significantly higher rate of a posttransplant reduced LVEF and an enlarged left ventricular size in patients with chronic digitalis therapy before HTX.

Differences between the two derivatives of digitalis digoxin and digitoxin - may have an impact on survival as the 
half-life and the mechanism of elimination differ. ${ }^{31}$ Digoxin has a half-life of about 2 days and is primarily excreted via the kidneys, while digitoxin has a half-life of about 6 days and is primarily excreted via the enterohepatic circulation. ${ }^{31}$ However, in this study, there was no significant difference between patients with digoxin or digitoxin therapy prior to HTX in 30-day or 2-year posttransplant survival.

Due to the narrow therapeutic window of digitalis, increased digitalis doses and elevated serum levels of digitalis have been linked to impaired survival. ${ }^{2,15,32}$ Again, in this study, there was neither a statistically significant difference between patients with low or high doses of digoxin before HTX in 30-day or 2-year survival nor between patients with low or high doses of digitoxin before HTX in 30-day or 2-year posttransplant survival.

In summary, the abovementioned results indicate that chronic digitalis therapy in patients before HTX is an independent risk factor for increased posttransplant mortality. Nonetheless, the abovementioned results indicate that survival after HTX may be affected by various parameters. So far, it is uncertain whether our results regarding the chronic use of digitalis before HTX can be applied to patients on the waiting list for HTX in general. Therefore, as the deleterious effects of digitalis are still not completely understood, digitalis in patients awaiting HTX should be used with utmost caution.

\section{Early posttransplant AF}

As a result of its properties, the use of digitalis may provoke the occurrence of supraventricular and ventricular arrhythmias. ${ }^{2}$ Furthermore, due to its stimulation of the activity of the vagus nerve, its negative chronotropic and dromotropic effects, as well as its positive bathmotropic effects, digitalis may render the atrium more susceptible to AF. 2,21-24

Patients with AF have an increased risk for thromboembolic events such as transient ischemic attack and stroke. ${ }^{33}$ Furthermore, patients suffering from AF after HTX have an impaired posttransplant survival, compared to patients with sinus rhythm. ${ }^{25,34,35}$ Additionally, even brief episodes of AF have been associated with unfavorable outcomes. ${ }^{35}$

Proarrhythmic effects of digitalis, especially the occurrence of AF, may be the result of drug interactions with other antiarrhythmic drugs. ${ }^{2,36}$ In a recent post hoc analysis of the PALLAS trial which compared the effects of dronedarone vs placebo on patients with AF and was stopped ahead of schedule for safety reasons, it was shown that 11 of 13 arrhythmic deaths in the dronedarone group occurred in patients receiving digoxin. ${ }^{37,38}$ The authors attribute this increased number of deaths to a drug interaction between digoxin and dronedarone at the level of the P-glycoprotein transport system causing elevated serum levels of digitalis., ${ }^{2,38}$ However, comparison of initial posttransplant medication in this study showed no significant differences between the digitalis group and the no digitalis group concerning the use of antiarrhythmic drugs such as $\beta$-blocker or calcium channel blocker, minimizing possible confounding.

There are several risk factors which may be related to the occurrence of early posttransplant AF, such as the type of surgical technique (biatrial, bicaval, or total orthotopic HTX). ${ }^{25}$ The biatrial technique consists of two long anastomoses of donor and recipient atria resulting in enlarged cavities with distorted anatomy, whereas the bicaval technique preserves the right donor atrium via donor-to-recipient venae cavae anastomoses. In the total orthotopic HTX, both donor atria are preserved by total excision of the recipient atria, except for two small pulmonary vein cuffs, which are integrated into the left donor atrium. The right donor atrium is preserved via donor-to-recipient venae cavae anastomoses as in the bicaval technique. ${ }^{25,39}$

In a previous study of our group, we could demonstrate that total orthotopic HTX had the lowest rate of AF (total orthotopic HTX: 6.3\%, bicaval HTX: 14.8\%, biatrial HTX: $17.4 \% ; P=0.0012) .{ }^{25}$ Moreover, an enlarged left atrium, mitral regurgitation, and valvular heart disease as the principal diagnosis for HTX have been related to the occurrence of early posttransplant $\mathrm{AF}{ }^{25}$

Oxidative stress has been connected to the pathogenesis of AF. ${ }^{40}$ Patients in the early posttransplant period are exposed to postoperative stress, including catecholaminergic imbalance, electrolyte imbalance, hypertension, or episodes of pain, increasing the likelihood of the occurrence of AF.

In this study, $11.5 \%$ of all patients had early posttransplant AF, which is in line with the reported rates of early posttransplant AF of $7.9 \%-18.2 \% .^{34,35}$ Regarding the occurrence of early posttransplant AF, we could not detect a statistically significant difference between patients with and without chronic digitalis therapy before HTX.

\section{Study limitations}

First, our results are derived from a single-center study. Nevertheless, due to its large number of 530 participants including 180 patients with chronic digoxin therapy before HTX, 167 patients with chronic pretransplant digitoxin use, and 183 patients without chronic digitalis administration prior to HTX, outcomes are comparable in participant numbers to multicenter trials. In addition, patients had a standardized center-specific pre-, peri-, and posttransplant treatment and 
follow-up, minimizing potential selection bias and confounders. Second, although data were collected prospectively, the retrospective nature of data analysis has certain limits. ${ }^{25-28}$

Third, a possible interaction between digitalis and the immunosuppressive drug regimen cannot be completely ruled out, although previous data could demonstrate that CsA has no specific inhibitory effect on the renal elimination of digoxin. ${ }^{41}$

Fourth, serum levels of digoxin or digitoxin directly before HTX were not available. Therefore, a potential association between increased posttransplant mortality and higher serum levels of digitalis could not be analyzed. Nevertheless, there was neither a significant difference between patients with digoxin/digitoxin nor with patients receiving low/high doses of digitalis in 30-day or 2-year posttransplant survival, indicating a dose-independent negative effect of digitalis on posttransplant mortality. Fifth, as a result of the extended period of follow-up, a potential era effect cannot be entirely excluded. ${ }^{25-30}$

Last, our findings should be considered as hypothesisgenerating, especially in regard to the results of survival, as several risk factors may cause reduced LVEF and an enlarged left ventricular size. Hence, to confirm our findings, further large prospective randomized controlled multicenter trials are needed to analyze the effects of chronic digitalis therapy before HTX on posttransplant outcomes.

\section{Conclusion}

The use of digitalis (digoxin or digitoxin) in patients with $\mathrm{HF}$ and/or AF is subject to an ongoing debate. As the effects of digitalis therapy in patients before HTX on posttransplant outcomes have been poorly studied, we performed the largest known study to investigate the effects of chronic digitalis therapy before HTX on early posttransplant mortality and AF. In this retrospective, observational, single-center study with 530 patients, a total of 347 patients received chronic digitalis therapy before HTX. Of these, 180 patients received digoxin and 167 patients had digitoxin.

Patients with chronic digitalis therapy before HTX had a significantly lower 30-day and 2-year survival. There was no significant difference between patients with digoxin or digitoxin before HTX in 30-day or 2-year survival. Multivariate analysis for posttransplant 30-day mortality showed pretransplant digitalis therapy as an independent risk factor. In terms of causes of death, significantly more patients died from transplant failure in the chronic digitalis group. Furthermore, patients with chronic digitalis use before HTX had a statistically significant higher percentage of a reduced LVEF and an enlarged left ventricular size.

Regarding the occurrence of early posttransplant AF, there was neither a significant difference between patients with or without digitalis nor between patients with digoxin or digitoxin.

In summary, chronic digitalis therapy in patients before HTX is an independent risk factor for increased posttransplant mortality.

\section{Acknowledgments}

This study was supported in part by research grants from the Faculty of Medicine, University of Heidelberg (Physician Scientist Scholarship to Ann-Kathrin Rahm). We acknowledge financial support by the Deutsche Forschungsgemeinschaft (DFG - German Research Foundation) and the University of Heidelberg within the funding program "Open Access Publishing”. We thank Viola Deneke and Berthold Klein for their assistance and advice.

\section{Disclosure}

The authors report no conflicts of interest in this work.

\section{References}

1. Digitalis Investigation Group. The effect of digoxin on mortality and morbidity in patients with heart failure. $N$ Engl J Med. 1997;336(8): 525-533.

2. Vamos M, Erath JW, Hohnloser SH. Digoxin-associated mortality: a systematic review and meta-analysis of the literature. Eur Heart $J$. 2015;36(28):1831-1838.

3. Corley SD, Epstein AE, DiMarco JP, et al. Relationships between sinus rhythm, treatment, and survival in the Atrial Fibrillation Follow-Up Investigation of Rhythm Management (AFFIRM) Study. Circulation. 2004;109(12):1509-1513.

4. Hallberg P, Lindbäck J, Lindahl B, Stenestrand U, Melhus H; RIKSHIA group. Digoxin and mortality in atrial fibrillation: a prospective cohort study. Eur J Clin Pharmacol. 2007;63(10):959-971.

5. Shah M, Avgil Tsadok M, Jackevicius CA, Essebag V, Behlouli H, Pilote L. Relation of digoxin use in atrial fibrillation and the risk of all-cause mortality in patients $\geq 65$ years of age with vs without heart failure. Am J Cardiol. 2014;114(3):401-406.

6. Turakhia MP, Santangeli P, Winkelmayer WC, et al. Increased mortality associated with digoxin in contemporary patients with atrial fibrillation: findings from the TREAT-AF study. J Am Coll Cardiol. 2014;64(7): 660-668.

7. Ouyang AJ, Lv YN, Zhong HL, et al. Meta-analysis of digoxin use and risk of mortality in patients with atrial fibrillation. Am J Cardiol. 2015;115(7):901-906.

8. Washam JB, Stevens SR, Lokhnygina Y, et al. Digoxin use in patients with atrial fibrillation and adverse cardiovascular outcomes: a retrospective analysis of the Rivaroxaban Once Daily Oral Direct Factor Xa Inhibition Compared with Vitamin K Antagonism for Prevention of Stroke and Embolism Trial in Atrial Fibrillation (ROCKET AF). Lancet. 2015;385(9985):2363-2370.

9. Madelaire C, Schou M, Nelveg-Kristensen KE, et al. Use of digoxin and risk of death or readmission for heart failure and sinus rhythm: a nationwide propensity score matched study. Int J Cardiol. 2016;221: 944-950.

10. Al-Khateeb M, Qureshi WT, Odeh R, et al. The impact of digoxin on mortality in patients with chronic systolic heart failure: a propensitymatched cohort study. Int J Cardiol. 2017;228:214-218.

11. Friberg L, Hammar N, Rosenqvist M. Digoxin in atrial fibrillation: report from the Stockholm Cohort study of Atrial Fibrillation (SCAF). Heart. 2010;96(4):275-280. 
12. Mulder BA, Van Veldhuisen DJ, Crijns HJ, et al. Digoxin in patients with permanent atrial fibrillation: data from the RACE II study. Heart Rhythm. 2014;11(9):1543-1550.

13. Ziff OJ, Lane DA, Samra M, et al. Safety and efficacy of digoxin: systematic review and meta-analysis of observational and controlled trial data. BMJ. 2015;351:h4451.

14. Wyse DG, Waldo AL, DiMarco JP, et al. A comparison of rate control and rhythm control in patients with atrial fibrillation. $N$ Engl J Med. 2002;347(23):1825-1833.

15. Whitbeck MG, Charnigo RJ, Khairy P, et al. Increased mortality among patients taking digoxin - analysis from the AFFIRM study. Eur Heart J. 2013;34(20):1481-1488.

16. Gheorghiade M, Fonarow GC, van Veldhuisen DJ, et al. Lack of evidence of increased mortality among patients with atrial fibrillation taking digoxin: findings from post hoc propensity-matched analysis of the AFFIRM trial. Eur Heart J. 2013;34(20):1489-1497.

17. van Veldhuisen DJ, Van Gelder IC, Ahmed A, Gheorghiade M. Digoxin for patients with atrial fibrillation and heart failure: paradise lost or not? Eur Heart J. 2013;34(20):1468-1470.

18. Murphy SA. When 'digoxin use' is not the same as 'digoxin use': lessons from the AFFIRM trial. Eur Heart J. 2013;34(20):1465-1467.

19. Goldberger ZD, Goldberger AL. Therapeutic ranges of serum digoxin concentrations in patients with heart failure. Am J Cardiol. 2012; 109(12):1818-1821.

20. Khan SS, Gheorghiade M. Digoxin use in atrial fibrillation: a critical reappraisal. Lancet. 2015;385(9985):2330-2332.

21. Levi AJ, Boyett MR, Lee CO. The cellular actions of digitalis glycosides on the heart. Prog Biophys Mol Biol. 1994;62(1):1-54.

22. Eichhorn EJ, Gheorghiade M. Digoxin. Prog Cardiovasc Dis. 2002; 44(4):251-266.

23. Longhurst JC, Ross J Jr. Extracardiac and coronary vascular effects of digitalis. J Am Coll Cardiol. 1985;5(5 Suppl A):99A-105A.

24. Somberg JC. Digitalis: neurally mediated arrhythmogenic and coronary vasoconstrictor properties. J Clin Pharmacol. 1985;25(7): 529-539.

25. Rivinius R, Helmschrott M, Ruhparwar A, et al. The influence of surgical technique on early posttransplant atrial fibrillation - comparison of biatrial, bicaval, and total orthotopic heart transplantation. Ther Clin Risk Manag. 2017;13:287-297.

26. Rivinius R, Helmschrott M, Ruhparwar A, et al. Comparison of posttransplant outcomes in patients with no, acute, or chronic amiodarone use before heart transplantation. Drug Des Devel Ther. 2017;11: 1827-1837.

27. Rivinius R, Helmschrott M, Ruhparwar A, et al. Long-term use of amiodarone before heart transplantation reduces significantly early post-transplant atrial fibrillation and is not associated with increased mortality after heart transplantation. Drug Des Devel Ther. 2016;10: $677-686$.
28. Rivinius R, Helmschrott M, Ruhparwar A, et al. Analysis of malignancies in patients after heart transplantation with subsequent immunosuppressive therapy. Drug Des Devel Ther. 2014;9:93-102.

29. Helmschrott M, Rivinius R, Ruhparwar A, et al. Advantageous effects of immunosuppression with tacrolimus in comparison with cyclosporine A regarding renal function in patients after heart transplantation. Drug Des Devel Ther. 2015;9:1217-1224.

30. Helmschrott M, Rivinius R, Bruckner T, Katus HA, Doesch AO. Renal function in heart transplant patients after switch to combined mammalian target of rapamycin inhibitor and calcineurin inhibitor therapy. Drug Des Devel Ther. 2017;11:1673-1680.

31. Smith TW. Pharmacokinetics, bioavailability and serum levels of cardiac glycosides. J Am Coll Cardiol. 1985;5(5 Suppl A):43A-50A

32. Rathore SS, Curtis JP, Wang Y, Bristow MR, Krumholz HM. Association of serum digoxin concentration and outcomes in patients with heart failure. JAMA. 2003;289(7):871-878.

33. Hohnloser SH, Pajitnev D, Pogue J, et al. Incidence of stroke in paroxysmal vs sustained atrial fibrillation in patients taking oral anticoagulation or combined antiplatelet therapy: an ACTIVE W Substudy. J Am Coll Cardiol. 2007;50(22):2156-2161.

34. Dasari TW, Pavlovic-Surjancev B, Patel N, et al. Incidence, risk factors, and clinical outcomes of atrial fibrillation and atrial flutter after heart transplantation. Am J Cardiol. 2010;106(5):737-741.

35. Pavri BB, O’Nunain SS, Newell JB, Ruskin JN, William G. Prevalence and prognostic significance of atrial arrhythmias after orthotopic cardiac transplantation. J Am Coll Cardiol. 1995;25(7):1673-1680.

36. Fromm MF, Kim RB, Stein CM, Wilkinson GR, Roden DM. Inhibition of P-glycoprotein-mediated drug transport: a unifying mechanism to explain the interaction between digoxin and quinidine. Circulation. 1999; 99(4):552-557.

37. Connolly SJ, Camm AJ, Halperin JL, et al. Dronedarone in high-risk permanent atrial fibrillation. $N$ Engl J Med. 2011;365(24):2268-2276.

38. Hohnloser SH, Halperin JL, Camm AJ, Gao P, Radzik D, Connolly SJ; PALLAS investigators. Interaction between digoxin and dronedarone in the PALLAS trial. Circ Arrhythm Electrophysiol. 2014;7(6): 1019-1025.

39. Jacob S, Sellke F. Is bicaval orthotopic heart transplantation superior to the biatrial technique? Interact Cardiovasc Thorac Surg. 2009;9(2): $333-342$.

40. Gasparova I, Kubatka P, Opatrilova R, et al. Perspectives and challenges of antioxidant therapy for atrial fibrillation. Naunyn Schmiedebergs Arch Pharmacol. 2017;390(1):1-14.

41. Robieux I, Dorian P, Klein J, et al. The effects of cardiac transplantation and cyclosporine therapy on digoxin pharmacokinetics. J Clin Pharmacol. 1992;32(4):338-343.
Therapeutics and Clinical Risk Management

\section{Publish your work in this journal}

Therapeutics and Clinical Risk Management is an international, peerreviewed journal of clinical therapeutics and risk management, focusing on concise rapid reporting of clinical studies in all therapeutic areas outcomes, safety, and programs for the effective, safe, and sustained use of medicines. This journal is indexed on PubMed Central, CAS,

\section{Dovepress}

EMBase, Scopus and the Elsevier Bibliographic databases. The manuscript management system is completely online and includes a very quick and fair peer-review system, which is all easy to use. Visit http://www.dovepress.com/testimonials.php to read real quotes from published authors. 